Volume 8, No.5, September - October 2019

International Journal of Advanced Trends in Computer Science and Engineering

Available Online at http://www.warse.org/IJATCSE/static/pdf/file/ijatcse120852019.pdf

https://doi.org/10.30534/ijatcse/2019/120852019

\title{
The Implication of Customer Relationship in Office Facility Management of Upstream Oil and Gas Business
}

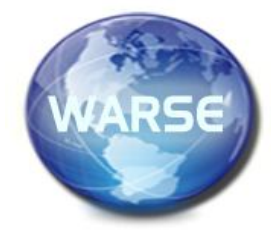

\author{
Nina Anggraini ${ }^{1}$, Gunawan Wang ${ }^{2}$ \\ ${ }^{1,2}$ Information Systems Management Department, \\ BINUS Graduate Program-Master of Information Systems Management, \\ Bina Nusantara University, \\ Jakarta, Indonesia \\ 1'nina.anggraini@binus.ac.id, ${ }^{2}$ gwang@binus.edu
}

\begin{abstract}
Many researchers have discussed the role of Customer Relationship Management (CRM) in the private and public sectors, especially in citizen-centered government agencies. However, there is still little effort to address the adoption of CRM in the field of oil and gas government agencies, mainly related to the office facilities management area. This paper seeks to fill this gap by discussing the implications of CRM in the office facility management and its implementation in the upstream oil and gas agency in the Republic of Indonesia. The study recommends a CRM strategy implemented on each element of people, process, and technology. This implementation is expected to provide office facility services that are more effective and efficient, also to increase customer satisfaction and employee productivity. The evaluation of CRM software, the selection of cloud computing solutions, as well as the use of a balanced scorecard to measure project performance, are also presented in the paper.
\end{abstract}

Key words: Customer Relationship Management, Office Facility Management, Upstream Oil and Gas, Cloud Computing.

\section{INTRODUCTION}

Since the 1990s, Customer Relationship Management (CRM) has been adopted by the private and public sectors [1]. It involves an organization taking a customer-centric view of its business to establish a long-term relationship with the customer [2]. The benefits of implementing CRM include increase customer trust, customer satisfaction, customer loyalty, and organization benefits [3]. Also, it helps the employees to organize their activities and provides reports and information for the organization that gives the potential for the organization to see new opportunities [4]. CRM is the methods, practices, and technology that organizations use in managing customers' interactions [5]. This understanding will help the organization effectively utilize the CRM system to understand what works best for their customers and where there is room for improvement [6]. The CRM approach has now been widely adopted by various sectors that have broader stakeholder growth, and many have implemented it successfully. [7].

The oil and gas industry has a significant role in the world energy market, and one of the most critical industries in Indonesia. The upstream operation includes the exploration and production which finding and producing petroleum and gas. The midstream segment includes markets and transports goods, such as petroleum, gas, and gas liquids. The downstream segment includes oil refineries, petrochemical products, dealers, and gas stations to distribute petroleum products to end consumers [8]. CRM has late developed to meet the needs of the oil and gas industry. CRM more likely used by downstream companies to support the entire downstream lifecycle [9]. There are still limited research efforts in the field of CRM in the upstream oil and gas business activities. Unlike downstream or other industries, the implementation of CRM in this sector is not straightforward. The customer of crude oil and natural gas is a company through a long process and bound by many regulations. At the early stages, a potential opportunity for the leading operator has not yet identified. Thus, it is difficult to link with a lead customer account and attach any activity, value, or forecasting before the main contract award. However, CRM technology can also be adopted by upstream oil and gas companies to manage their relationships with customers and their stakeholders, to track information effectively and develop their organizational capabilities.

This paper explores the impact of CRM in the upstream oil and gas industry from the perspective of government agency regulating this business in the Republic of Indonesia. The agency encouraged to have better office facility management utilizing current technology initiatives, which CRM system is one of the possible solutions. The implementation of CRM helps the agency dealing with various oil and gas companies by linking and managing multiple key contacts who influence 
the channel. CRM software provides a centralized database that stores documents, attachments, communications, offers, pending assignments, service contracts, and service issues. It ensures all of them are available to employees across the agency as a whole. CRM software enables accelerating decisions based on secure information regarding contracts and vendors' details to create a dashboard that shows status by using databases. The cloud CRM software services model is chosen to be implemented by the agency because it provides flexibility, cost-effective as well as easy maintenance and deployment with high-security level. The agency pays according to the services used, such as appropriate storage capacity and maintenance support costs, without requiring significant initial costs. At the end of the project, a balanced scorecard was used to measure the performance of the Cloud-CRM project implementation from four perspectives: financial, customer, internal processes, and learning and growth [10].

\section{LITERATURE STUDY}

This section will describe the philosophy, strategy, and technology of CRM. Knowing the basic concept will assist the agency in understanding how CRM is expected to help them improve, particularly in the office facility management area.

\subsection{CRM}

CRM is the entire idea and effort on how to effectively manage customer relationships. The center and also the object of interest is the customer and their needs. CRM is the management of a company's interactions with customers [6], [7]. In business terms, CRM is a strategy to build customer loyalty by developing long-term, mutually beneficial relationships using the latest advances in information processing technology [11]. In Information Technology (IT) terms, CRM is a tool to support the CRM philosophy and strategy of the organization, so that the management of customer relations is more efficacious [12]. CRM systems collect data about customers, contacts, transactions, and activities. It also involves the exchange of information or services between enterprises and customers. For the agency, CRM may leverage customer history data, getting to improve all relationships and interactions with customers. CRM ensures the organizations can effectively devise successful strategies that allow for more excellent process and performance improvements in eventually enabling lower operational costs.

The success of CRM strategy depends on three crucial organizational resources: people, technology, and processes [13]. Organizations need to work effectively to balance these three resources so that CRM can be used optimally to achieve high levels of customer satisfaction. [14]. In the case of people as a resource, when adopting a CRM strategy, organizations must provide training and motivation so that their employees understand and commit to customer-centered strategies and always try to meet customer expectations and needs [15]. Employees as executors of business activities have an important role in managing the relationship between the organization and its customers [16]. The second important resource in CRM strategies is technology. Digital-based technology can make a significant contribution to improving an organization's business processes, while the process is the third fundamental source of CRM strategies. One of the main results of implementing a CRM strategy is to change and create processes. CRM affects all processes in the organization so that it becomes more customer-oriented, both directly and indirectly engaging with customers [17].

There are three types of CRM technology approaches Operational CRM, Analytical CRM, and Collaborative CRM [6]. Operational CRM relates to serving process automation and streamlining workflow at the front office, which includes customer data collection and retrieval, as well as transaction process, control, monitoring, and reporting [2], [7]. Operational CRM makes sure the agency comes up with standards that allow them to improve the customer-related processes. Analytical CRM is all about using customer data to improve customer and organizational value. It builds on existing operational CRM, providing analytical data using statistical analysis tools especially data mining [2], [7]. Analytics CRM can help agencies become more productive by analyzing data, understanding what is lacking, finding the best customer approach, and offering high-quality services. Collaborative CRM allows the agency to be able to share information across several units [2], such as the support team, technical team, or management team. Collaborative CRM is the ability to work together, providing solutions that can be offered to customers. It utilizes communication technologies such as telephone, fax, e-mail, and website that customers can use to interact with the organization [7].

\subsection{CRM in Upstream Oil and Gas Business}

The key concept of CRM that needs to be emphasized is the customer chain [18], how every member of the customer chain share data, and how to ensure the synergies between the links in the chain. In terms of office facility management, some customers are the external customer who is directly purchasing the product or service, and an internal customer is a group in the organization that gets processes, services, and products from another in the distribution channel. External customers in the upstream oil and gas industry can consist of a variety of private and public organizations, from multinational companies to other government agencies. Effective relationship management in oil and gas should also consider other stakeholders [19]: oil and gas contractors, 
consultants, or vendors, and the employee as internal customers.

\subsection{Office Facility Management and CRM}

Office Management is a branch of management that deals with efficient office performance [20]. In carrying out its activities in an office, employees in an organization need facilities that support their work in achieving organizational goals. Facilities are all things that are used, used, occupied, by employees both in environmental relations with work and for the smooth running of work. Office facilities include facilities and infrastructure that are used in physical activity, have a relatively permanent period of usefulness, and provide benefits for the future [21]. Office facility management can be defined as planning, controlling, and organizing office facilities, and mobilizing those who carry out in order to achieve predetermined goals [22]. Office facility management aims to strive for office facilities and infrastructure to be ready for use, as well as to provide professional services in the field of facilities and infrastructure. The ultimate goal of managing office facilities is to increase the effectiveness and efficiency of employee performance.

CRM, as a management philosophy and set of strategic and operational tools, may bring improvement in office facility management through innovations, which includes innovation in process, innovation in administrative affairs, and innovation in services [3]. Those innovations can be delivered by executing and implementing a new or improved method that can be in the form of software which is used in offering office facility services. The goal of innovation is increasing agency performance by decrease costs or improving satisfaction in the work environment [23]. The CRM software, if implemented correctly, may improve data collection and analysis on critical customer relationships, which will improve both strategic and operational level decision-making of office facility management.

CRM strategies and technology can help ensure that customers get sustainable service performance in all areas. From the perspective of the service provider, they help to ensure longer-term sustainable relationships with the agency. The success of CRM depends on the customer-focused strategy adopted by the organization. This is done including reengineering existing processes that interact with customers, or even in some organizations, new process designs are needed [24]. In terms of being more customer-centered, the agency must analyze customer problems based on experience and available data, then respond to support their needs. CRM requires alignment with changing customer needs based on integrated and reliable customer information. A CRM system can provide clear communication and traceability of customer requirements. The integration of CRM and ERP systems can enhance the quality of the office facility management at the macro level and in a customer-centered manner. The agency realized that adopting a CRM strategy would help the organization to increase staff productivity as well.

\subsection{Cloud CRM}

Cloud technology has gradually been applied in various fields [25]. Cloud CRM uses distributed computing to enable customers to access services from anywhere, anytime, on the internet. CRM software using the cloud service model has been widely studied and become a trend nowadays. According to [26], Cloud Software as a Service (SaaS) is the best service model that organizations can adopt in implementing CRM. Users only need a computer, smartphone, or tablet PC web browser to use SaaS CRM. Thus, they can achieve full productivity even when they are traveling in a business way, and business processes become more mobile. The benefits of using cloud CRM are the minimum need for investing in IT infrastructure and less administrator support for maintaining the application, which is become the responsibility of the cloud provider. The service will be more flexible and on-demand. for the actual computational and storage capacity used, without requiring a large initial capital outlay, which can reduce investment costs in the long run. Cloud computing generally allows organizations to manage their data and information more effectively and enables it to provide better customer services [26].

However, it is necessary to consider the disadvantages of this model, such as limited to customization, limited integration with other information systems, storage of sensitive data in the server of the service provider, and security problems such as data loss, data breaches [27]. Thus, the details of the contract with cloud providers must be clarified and considered carefully to ensure that the services meet the needs of the customer [28] - for example, the user privilege, the access protocol to the actual database, and reports if necessary. Vendor lock-in is the other disadvantage of cloud solution [29], which might be a big concern for a government organization that should comply with the National Public Procurement Agency regulation.

\subsection{Balanced Scorecard}

In the early 1990s, Kaplan and Norton [32] proposed the balanced scorecard (BSC) approach for identifying key business performance measures with an outward customer focus as well as internal employee and financial measures. Developing a BSC can help the agency to transform strategies into measurable goals that are related to financial, customer, internal processes, and learning and growth. Researchers [25] proposed CRM project performance measurement, as shown in Table 1. 
Table 1: CRM Project Performance Criteria

\begin{tabular}{|c|l|}
\hline Perspective & \multicolumn{1}{c|}{ Criteria } \\
\hline Financial & $\begin{array}{l}\text { The CRM project has a favorable investment } \\
\text { of opportunities. }\end{array}$ \\
\hline Customer & $\begin{array}{l}\text { The CRM project outcomes meet users' } \\
\text { needs. }\end{array}$ \\
\hline Internal Process & $\begin{array}{l}\text { The CRM project development process is } \\
\text { efficient. }\end{array}$ \\
\hline $\begin{array}{c}\text { Learning and } \\
\text { Growth }\end{array}$ & $\begin{array}{l}\text { The CRM project provides personal or } \\
\text { organizational learning and growth } \\
\text { opportunities. }\end{array}$ \\
\hline
\end{tabular}

\subsection{Related Works}

We explored related work related to "CRM in the oil and gas industry" and "CRM in the office facility management," then spread the search in similar industries or areas. We found that limited researchers have discussed the implication of CRM for the upstream oil and gas industry, specifically in the office facility management area.

Ch. Preece, H.Y. Chong, H. Golizadeh, J. Rogers [5] in their study "A review of customer relationship (CRM) implications: benefits and challenges in construction organizations" provides an overview of CRM philosophy and technology by considering the implications of benefits and challenges for companies engaged in construction at the strategic and operational levels. Their approach is compatible with general trends in the oil and gas industry towards more collaborative working processes.

Guy-Emmanuel Rigo, Cristiane Drebes Pedron, Mário Caldeira, Cíntia Cristina Silva de Araújo [30] in their study "CRM Adoption in a Higher Education Institution" concludes CRM project must consider other stakeholders than the primary customer. In the agency's case, the office support team serves not only the customer but also the stakeholder. This paper shows an effective CRM methodology to define more explicit, objective, and precise requirements. By which it resulted in meeting user's expectations and organizational strategic goals.

Peyman Ghafari, Reza Karjalian, Ali Mashayekhnia [3] in their study "Studying the Relationship between Different Dimensions of CRM and Innovation Capabilities in Melli Bank of Iran" investigated the relationship between various dimensions of CRM with the innovation capabilities of the organization. Among them are process innovation, administrative innovation, and service innovation that can be adapted by the agency. It covers the CRM in the back office area as well as the front office, such as customer services.

\section{METHODOLOGY}

Our research that encompassed a study case in an upstream oil and gas government agency was developed with a qualitative approach. We conducted analysis based on discussions with employees, management, and customers as primary data. Besides that, we collected the agency's policies and procedures, research papers, and websites with a similar topic as secondary data. M. Almotairi [17] proposes a conceptual framework that can be used to ensure the success of CRM implementation by integrating the CRM implementation phase, CRM components, and CRM success factors. CRM frameworks could serve as a guide for enhancing the potential to gain expected outcomes from CRM implementation successfully. CRM definition for this research is an attempt to integrate Process, People, and Technology cross-functionally in order to understand the organization's customers, improve stakeholder value, increase productivity, and achieve cost efficiency. Therefore, CRM success factors lie in how organizations manage, integrate, and control CRM components. The framework is shown in Figure 1.

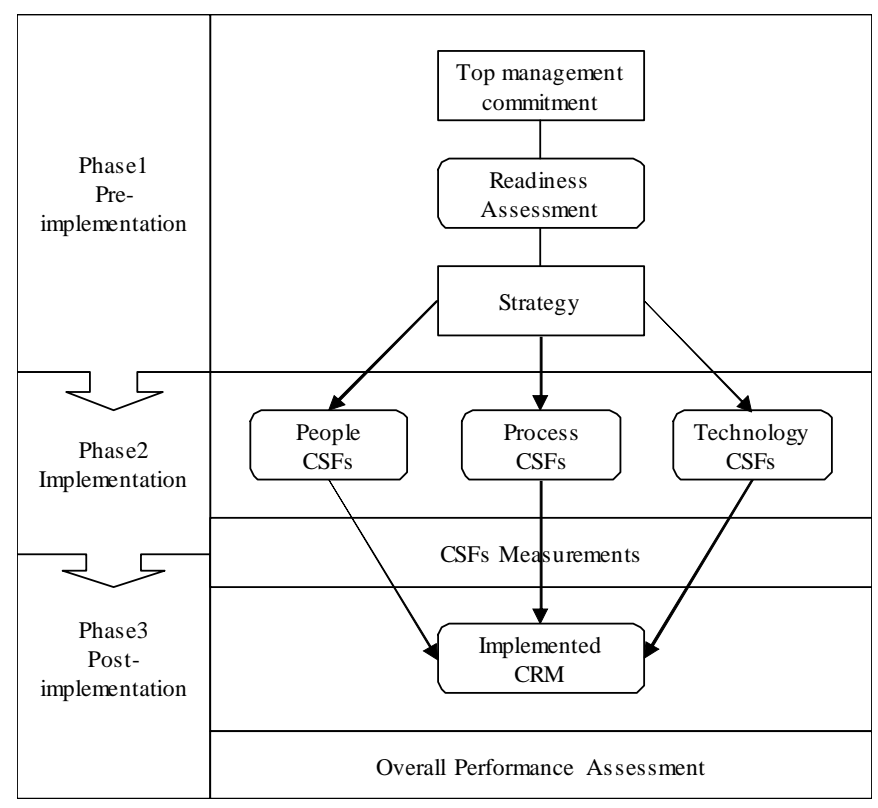

Figure 1: CRM Framework (source: Almotairi, 2009)

Our methodology leads to the arrangement of our paper. First, we identify the problem and objectives. We define the question of this research as "How CRM impact the upstream oil and gas business activities, particularly in the office facility management process?" Next, we analyze the CRM strategy and technology in terms of a business-centric government agency. We also analyze the business characteristic and customer value chain of upstream oil and gas industry, and how CRM may influence the office facility management process. Then, we develop a customer-focused process and design how CRM technology helps the agency in 
improving the office facility management process, increasing productivity, and lowering cost. Last, we provide discussion, summarize the finding, and recommend further research.

\section{DISCUSSION}

Upstream oil and gas is a complex industry, with many different stakeholders having different assumptions regarding CRM solutions. Therefore, implementing CRM software requires a thorough analysis of the main business requirements that cover the needs of all stakeholders [31]. As the agency goes through the process of selecting a CRM solution that best suits business needs, they need to design clear and objective requirements [13]. From the technology aspect, cloud CRM provides not only the database needed to store customer data but also the necessary tools to improve the office facility management processes.

Then, the agency analyzes the technology solutions available in the market. In this phase, the agency must follow existing guidelines to choose the right solution that suits the needs of the organization, such as laws and regulations, also internal policies, standards, and blueprints. The agency also analyzes alternatives available in the market and through benchmarking, analyzes software solutions that have been adopted by other similar agencies. Next, analyze the business needs and service issues from the view of all stakeholders. The author interviewed office supports, staff, and managers and collected their answers to identify CRM software requirements. During the market analysis step, the agency selected several CRM software based on the technical characteristics of the software, such as the fulfillment of business requirements and suitability of the solution according to the information technology architecture.

\subsection{Pre-Implementation}

Top management commitment was fundamental in implementing any project in the organization, including the CRM system [32]. Many researchers have proved the positive relationship between the top management support and the success rate of the project [4]. In the agency, the Deputy has actively supported the CRM project. He was able to monitor the external environment and have a good strategy. The Vice President of Strategic Management and Information Technology and Vice President of Office Facility and Security are assigned to monitor and evaluate the project performance. The VP of Office Facility and Security was the business owner of CRM strategy and implementation. The VP of Strategic Management and Information Technology supported the implementation of new technology. A technical team was established to manage the project closely, in which the author was joined and involved in every project phase. The Team reported to two VPs for any progress and problems.
Readiness assessment of the organization was conducted at the beginning of the project phase so the Team could define the suited strategy of CRM implementation. Participation and opinions of end-users are very important for the Team to understand their expectations regarding the CRM solution to be built. Thus, the Team conducted a discussion with the representation of employees, customers, office supports, and IT administrators, as well as an interview with the top management. The introduction of the CRM strategy in the office facility management required changes in the business process and introduced new technology. Through the discussion and interview, the Team was able to define a clear vision of the CRM and more precise requirements for software selection. The Team summarized the finding and categorized into internal organizational strengths and weaknesses and external opportunities and threats, which are shown in Table 2.

Table 2: SWOT Analysis

\begin{tabular}{|l|l|}
\hline & $\begin{array}{l}\text { The commitment of Top Management. } \\
\text { Employees, customers, office supports, and IT } \\
\text { administrators are well informed and welcoming the } \\
\text { change. }\end{array}$ \\
\hline $\begin{array}{l}\text { The need for organizational culture and process } \\
\text { changes. }\end{array}$ \\
Office supports have not aware yet with the concept of \\
CRM. \\
Lack of IT Administrators with many current \\
applications to be maintained.
\end{tabular}

In evaluating CRM technology, the Team should include alignment with the agency's business process strategy and goals, especially in terms of office facility management area. Identifying organizational needs and breaking down strategic objectives into more specific targets can help in defining the technical requirements of a CRM solution. Platform selection should comply with ICT Blueprint, including the ability to deliver the right data to the right employees and sufficient ease of adoption and use. Considering the SWOT analysis result, the Team proposed the cloud application service to answers some challenges regarding the lack of resources in the agency. It was the first time the agency embracing cloud technology, so the team has to analyze carefully. They enhanced their knowledge by discussions with the cloud 
provider, benchmarks to similar organizations, and analyze the regulations regarding the cloud in the Republic of Indonesia. Choosing a configurable and easy to use cloud-based software is essential so that the CRM solution can adapt to the specific needs of each group of users, including the top management. Being given complete analysis includes pros and contras compared to other options. The management approved and supported the use of cloud-based CRM software.

The Team prepared Request for Proposal and found three different cloud providers that able to provide the solution needed by the agency. Then, the Team submitted the Term of Reference along with responded proposals to the Procurement Team. They proceeded the tender and appointed one cloud vendor as the CRM implementer. By the time the tender has finished, the Team completed the strategy and communication, so all members of the organization were ready.

\subsection{Implementation}

Researchers have identified three strategic factors in the successful implementation of a CRM system at the business level: people, processes, and technology [32]-[34]. Under each, the Team defined the benefits need, conducted risk assessment, and identified Critical Success Factors (CSFs).

People: As a starting point, the Team ensures each group in the organization understands the essence of CRM, the need for change, and ensure they are welcoming it. The Team gathered feedbacks, then answered every doubtful question about the implementation, at the same time, convinced them that the new technology would benefit the organization as well as the customers. This two-way communication is smoothing the achievement of first CSF for the agency, which is culture change: how to create transformation into customer-oriented as one of organization philosophy.

Processes: The Team analyzed its current business processes regarding office facility management, and after the new cloud-based CRM software is implemented. The Cloud-CRM may not customizable enough to follow current processes, so the Team should identify which process would be accommodated or need to be changed following the software flow process. This process redesign is the CSF for the agency: how to develop necessary changes in the office facility process to fit cloud-CRM compatibility, including the hierarchy and reporting relations.

Technology: The Team set the configurations based on the organization structure and CRM strategy defined in the pre-implementation process, such as the needs of customer information and reporting. The agency implemented the strategy using cloud CRM software gradually. Customer service is chosen as the first module to be developed. To minimize the possibility of sensitive data leakage, in the first phase of the implementation, the cloud-CRM was not being integrated automatically with the current system, such as ERP. The export-import database mechanism is replacing this automated process. In the next six months after the system goes live, the Team planned to test the cloud-CRM security, evaluate the result, and consider the integration with current systems. For this element, the team identified the CSF is cloud technology adoption: how to adopt the cloud-CRM technology and integrate with the current system securely.

\subsection{Post-Implementation}

In the post-implementation phase, the Team transformed the three CSFs into project performance measurement BSC. Table 3 shows the criteria for each Financial, Customer, Internal Process, and Learning \& Growth. In this phase, the Office Support began using Cloud-CRM applications in their routines. During this evolution, one staff member was assigned to supervise and assist them. Cloud-CRM was tested in pilot implementation before launched to all customers.

Table 3: Project Performance Measurement

\begin{tabular}{|c|l|}
\hline Perspective & \multicolumn{1}{c|}{ Criteria } \\
\hline Financial & $\begin{array}{c}\text { The cloud -CRM project actual cost is } \\
\text { within the budget that was approved by } \\
\text { the Ministry of Finance. } \\
-\begin{array}{l}\text { The cloud -CRM project ROI is within } \\
\text { three years. }\end{array}\end{array}$ \\
\hline Customer & $-\begin{array}{l}\text { 90\% of customer requests and complains } \\
\text { are delivered using cloud-CRM. }\end{array}$ \\
& $-\begin{array}{l}\text { Customer feedback on cloud-CRM is } \\
\text { above 70\% satisfaction. }\end{array}$ \\
\hline Internal Process & $-\begin{array}{l}\text { 100\% approval of the office facility } \\
\text { management process is delivered using } \\
\text { cloud-CRM workflow. } \\
\text { The requests are delivered within the } \\
\text { Service Level Agreement. }\end{array}$ \\
\hline Learning and & $-\begin{array}{l}\text { Training for key users is delivered before } \\
\text { the system goes live. }\end{array}$ \\
Growth & $\begin{array}{l}\text { Cloud-CRM project evaluation and } \\
\text { lesson learn is delivered in six months of } \\
\text { the implementation. }\end{array}$ \\
\hline
\end{tabular}

\section{CONCLUSION}

A customer-centered culture needs to be built as CRM software is implemented. Fortunately, building a CRM philosophy requires time to integrate business requirements, user expectations, and technology. The literature shows that continuous adjustments in organizational processes, culture, and strategy can positively influence CRM results [13]. The primary customer for office facility services is the employees. However, other stakeholders should be considered, such as other government agencies, the oil and gas companies, and 
consultants. CRM can help organizations to develop a comprehensive view of customers and stakeholders and create strategies to be closer to them.

The agency needs to manage effectively three major organizational resources, people, processes, and technology. Concerning people, the agency needs to manage user expectations and training people. All user roles received a personalized training module to meet their specific demands. In this study case, the employees developed an understanding of how and why organizations improve a relationship with customers. That perspective helped the organization to accept the cultural change. Concerning process, the agency simplifies the office facility management process, following the Cloud-CRM process flow. The new process cut many bureaucracies and paper works, although the process needs to be adequately informed to all employees and customers. Concerning technology, as in the CRM software selection process, the agency showed big concern regarding software integration and suppliers of that specific software. Using cloud-based CRM applications can be very effective. The SaaS model is offered customizable software that suits the agency's needs. This form of CRM allows organizations to achieve cost reduction, flexibility, and convenience.

The limitation of the paper is that our research did not cover the post-implementation evaluation of the Cloud-CRM application, as the time limitation of the research. Such analysis will enable organizations to have a broader perspective on the impact of Cloud-CRM on their business processes and customer relationships. Thus, we suggest longitudinal research to analyses the impact of Cloud-CRM on organizational performance and how Cloud-CRM added (or did not) value. Since the surrounding environment of oil and gas companies (its size, geographical condition, technologies, and many other critical factors) can considerably similar to each other, it seems this practice of Cloud-CRM might work for the whole oil and gas sector. However, this needs further study, as well.

\section{REFERENCES}

[1] Y. Li, Z. Xiao, and F.-S. Liu, Classification of clients in Client Relationship Management (CRM) base on rough set theory, in Proceedings of the 2003 International Conference on Machine Learning and Cybernetics (IEEE Cat. No. 03EX693), 2003, vol. 1, pp. 242-246.

[2] K. Rababah, Customer Relationship Management (CRM) Processes from Theory to Practice: The Pre-implementation Plan of CRM System, International Journal of e-Education, e-Business, e-Management and e-Learning, vol. 1, no. 1, pp. 22-27, 2013.

[3] P. Ghafari, R. Karjalian, and A. Mashayekhnia,
Studying the relationship between different dimensions of CRM and innovation capabilities in Melli bank of Iran, World academy of science, engineering and technology, vol. 60, no. 12, pp. 906-910, 2011.

[4] A. Al-Arafati, U. Utara, M. Kadzrina, and A. Kadir, The Mediating Effect of Output Quality on the Relationship Between Top Management Support and Customer Satisfaction on the Implementation of Customer Relationship Management System in Public Sector, Academy of Strategic Management Journal, vol. 18, no. 2, pp. 1939-6104, 2019.

[5] C. Preece, H. Chong, H. Golizadeh, and J. Rogers, A review of customer relationship (CRM) implications: benefits and challenges in construction organizations, International Journal of Civil Engineering, vol. 13, no. 3, pp. 362-371, 2015.

[6] F. Khodakarami and Y. E. Chan, Exploring the role of customer relationship management (CRM) systems in customer knowledge creation, Information and Management, vol. 51, no. 1, pp. 27-42, 2014.

https://doi.org/10.1016/j.im.2013.09.001

[7] A. Idzikowski, P. Kuryło, J. Cyganiuk, and M. Ryczko, Customer Relationship Management (CRM) - Philosophy and its Significance for the Enterprise, System Safety: Human - Technical Facility - Environment, vol. 1, no. 1, pp. 1004-1011, 2019.

https://doi.org/10.2478/czoto-2019-0127

[8] M. Nassiry and M. Mukhtar, Business Type Classification via E-commerce Stage Model in Oil Industry in Iran, International Journal of Computer Science and Information Security (IJCSIS), vol. 12, no. 6, 2014.

[9] M. J. Khan, A Study Of Customer Relationship Marketing Practices (CRMP) Of Indian Oil Corporation (IOC), Aligarh Muslim University, 2015.

[10] R. S. Kaplan and D. P. Norton, Linking the balanced scorecard to strategy, California management review, vol. 39, no. 1, pp. 53-79, 1996. https://doi.org/10.2307/41165876

[11] A.-M. Croteau and P. Li, Critical success factors of CRM technological initiatives, Canadian Journal of Administrative Sciences/Revue Canadienne des Sciences de l'Administration, vol. 20, no. 1, pp. 21-34, 2003.

[12] M. Kaoud, Technological factors supporting Customer Knowledge Management: A case study research, in European Conference on Knowledge Management, 2018, pp. 1039--XX.

[13] P. Adrian, Handbook of CRM: Achieving Excellence in Customer Management. 2005.

[14] I. J. Chen and K. Popovich, Understanding customer relationship management (CRM) People, process and technology, Business process 
management journal, vol. 9, no. 5, pp. 672-688, 2003.

https://doi.org/10.1108/14637150310496758

[15] C. Brito, Relationship marketing: old wine in a new bottle?, Innovative Marketing, vol. 7, no. 1, pp. 66-77, 2011.

[16] M. Tekin, Critical Success Factors for a Customer Relationship Management Strategy, Mediterranean Journal of Social Sciences, vol. 4, no. 10, pp. 753-757, 2013.

[17] K. A. Richards and E. Jones, Customer relationship management: Finding value drivers, Industrial marketing management, vol. 37, no. 2, pp. 120-130, 2008.

[18] J. Wei, L. Van Der Ende, and B. Lin, Customer-focused e-business model for the oil industry, Journal of Computer Information Systems, vol. 49, no. 3, pp. 11-21, 2009.

[19] R. B. Handfield and C. Bechtel, The role of trust and relationship structure in improving supply chain responsiveness, Industrial marketing management, vol. 31, no. 4, pp. 367-382, 2002.

https://doi.org/10.1016/S0019-8501(01)00169-9

[20] W. H. Leffingwell, E. M. Robinson, and others, Textbook of office management, 1950.

[21] Z. K. Quible, Administrative office management: an introduction. Prentice Hall, 2001.

[22] G. R. Terry, Office Management and Control. Ilionis: Richard D. Irwin Inc., 2009.

[23] P. S. Mortensen, C. W. Bloch, and others, Oslo manual-guidelines for collecting and interpreting innovation data: Proposed guidelines for collecting and interpreting innovation data, 2005.

[24] B. Hansotia, Gearing up for CRM: Antecedents to successful implementation, Journal of Database Marketing \& Customer Strategy Management, vol. 10, no. 2, pp. 121-132, 2002.

[25] Y.-S. Chen, C.-K. Lin, and H.-M. Chuang, Closing the Skill Gap of Cloud CRM Application Services in Cloud Computing for Evaluating Big Data Solutions, ISPRS International Journal of Geo-Information, vol. 5, no. 12, pp. 227-246, 2016. https://doi.org/10.3390/ijgi5120227

[26] J. Němeček and L. Valvnková, CRM and cloud computing, in Proceedings of the 2nd international conference on applied informatics and computing theory. World Scientific and Engineering Academy and Society (WSEAS), 2011, pp. 255-259.

[27] K. Lakshmaiah, E. Foundation, and A. Pradesh, Cloud Computing: Review on Recent Research Progress and Issues, International Journal of Advanced Trends in Computer Science and Engineering, vol. 8, no. 2, pp. 216-223, 2019. https://doi.org/10.30534/ijatcse/2019/18822019

[28] C. K. Fan and T.-C. Chen, The Risk Management Strategy of Applying Cloud Computing, International Journal of Advanced Computer Science and Applications (IJACSA), vol. 3, no. 9, pp. 18-27, 2012.

[29] K. Jyothi and R. Karthik, Cloud connectivity for embedded systems, International Journal of Advanced Trends in Computer Science and Engineering, vol. 8, no. 3, pp. 731-733, 2019. https://doi.org/10.30534/ijatcse/2019/61832019

[30] G.-E. Rigo, C. D. Pedron, M. Caldeira, and C. C. S. de Araújo, CRM Adoption in a Higher Education Institution, Journal of Information Systems and Technology Management, vol. 13, no. 1, pp. 45-60, 2016.

[31] S. Sindakis, A. Depeige, and E. Anoyrkati, Customer-centered knowledge management: challenges and implications for knowledge-based innovation in the public transport sector, Journal of Knowledge Management, vol. 19, no. 3, pp. 559-578, 2015.

https://doi.org/10.1108/JKM-02-2015-0046

[32] M. Almotairi, A Framework for Successful CRM Implementation, European and Mediterranean Conference on Informa?on Systems, vol. 2009, pp. 1-14, 2009.

[33] D. Laney, The great enterprise balancing act: Extended Relationship Management (XRM), META Group publication, 2001.

[34] P. Greenberg, CRM at the Speed of Light: Social CRM Strategies, Tools, and Techniques. McGraw-Hill, 2010. 